\title{
Analisis Strategi Tindak Tutur Nasihat (Jogen) dalam Jenis Film Live Action
}

\author{
${ }^{1}$ Poppy Rahayu, ${ }^{2}$ Nur Saadah Fitri Asih, ${ }^{3}$ Rosita Rinjani \\ Universitas Negeri Jakarta, Indonesia \\ 1poppyrahayu.sabri@gmail.com \\ 2nursaadahfitri@unj.ac.id \\ 33rositarinjani@gmail.com
}

DOI: $10.18196 /$ jjlel.4240

\begin{abstract}
Abstrak
Penelitian ini bertujuan untuk mengetahui bentuk tindak tutur nasihat (jogen) dan strategi tindak tutur nasihat (jogen). Hal ini dilatarbelakangi oleh fenomena bahwa memberikan nasihat (jogen) cenderung menyebabkan lawan bicara merasa tersinggung, dan nasihat tersebut dapat dianggap sebagai kritik negatif, walaupun bertujuan untuk membantu lawan bicara dalam menyelesaikan masalah yang dihadapi. Penelitian menggunakan referensi teori dari Kumatoridani dan Murakami (dalam Takahashi, 2017: 14) tentang strategi penyampaian nasihat (jogen). Teori ini menyoroti bahwa menawarkan nasihat harus didasarkan pada konteks situasi yang dapat menghibur lawan bicara. Strategi penyampaian nasihat yang diungkapkan dalam penelitian ini yaitu: (a) X の提示 merupakan tindakan yang dilakukan oleh pembicara yang seharusnya dilakukan oleh lawan bicaranya, (b) S1 の提 示, mengacu pada situasi saat ini atau yang akan datang yang tidak diinginkan oleh lawan bicaranya, (c) S2 の提示, pembicara berbicara tentang situasi yang lebih diinginkan oleh lawan bicaranya, dan (d) ) X + S1 の提示, (e) X + S2 の 提示, (f) $\mathrm{S} 1+\mathrm{S} 2$ の提示, and (g) X + S1 + S2 の提示 yang merupakan gabungan dari strategi (a) dan (c). Penelitian ini menggunakan metode referensi dan teknik membuat catatan untuk mengumpulkan data dari film live action dan metode identitas referensial yang digunakan untuk analisis data. Berdasarkan hasil penelitian, dapat disimpulkan bahwa bentuk tindak tutur nasihat (jogen) dan pemilihan strategi tindak tutur nasihat (jogen) dipengaruhi oleh jenis hubungan antara partisipan dengan masalah yang dialami oleh lawan bicara. Bentuk tindak tutur nasihat (jogen) meliputi saran, nasihat, pendapat, perintah, larangan, kewajiban, praduga, dan pemberian informasi. Strategi yang digunakan adalah X の提示, S1 の提示, S2 の提示, X
\end{abstract}


+ S1 の提示, $\mathrm{X}+\mathrm{S} 2$ の提示, $\mathrm{X}+\mathrm{S} 1+\mathrm{S} 2$ の提示 dan ada kombinasi antara dua bentuk strategi yaitu $X+S 1$ の提示 kemudian dilanjutkan dengan strategi $\mathrm{X}+\mathrm{S} 1+\mathrm{S} 2$ の提示.

Kata Kunci: jogen; nasihat; pragmatik; strategi; tindak tutur

\begin{abstract}
This study aims to identify the form of speech advice (jogen) and speech act of advice (jogen) strategies. It is based on the background that giving advice (jogen) tends to cause the interlocutor to feel offended, and the advice can be considered as negative criticism, although it aims to help the interlocutors to solve the problem that they encounter. This study used the reference theory by Kumatoridani and Murakami (in Takahashi 2017: 14) regarding the strategy of delivering advice (jogen). The theory highlights that offering advice must be based on the context of the situation that can comfort the interlocutors. The strategies of delivering advice revealed by them are such as (a) X の提示 namely the speakers utter actions that should be done by the interlocutor, (b) S1 の提示, i.e., referring to a present or future situation that is not intended by the interlocutor, (c) S2 の提示, i.e., speakers speak about the situations more intended by the interlocutor, and (d) $X+S 1$ の提示, (e) X + S2 の提示, (f) S1 $+\mathrm{S} 2$ の提示, and $(\mathrm{g}) \mathrm{X}+\mathrm{S} 1+\mathrm{S} 2$ の提示 which is a combination of strategy (a) and (c). This study used the reference method and note-taking technique to collect data from live-action and referential identity methods for data analysis. Based on the results of the study, it can be concluded that the form of speech of advice (jogen) and the choice of the speech act of advice (jogen) strategy are influenced by the type of relationship between participants and the problems experienced by the interlocutor. Form of speech of advice (jogen) included suggestions, advice, opinions, orders, prohibitions, obligations, presuppositions, and provision of information. The strategy used was $X$ の提示, $S 1$ の提示, $S 2$ の提示, $X+S 1$ の提示, $X+S 2$ の提示, $X+S 1+$ S2 の提示 and there was a combination between two forms of strategy namely $\mathrm{X}+\mathrm{S} 1$ の提示. It was then followed by the strategy $\mathrm{X}+\mathrm{S} 1+\mathrm{S} 2$ の提示.
\end{abstract}

Keywords: advice; jogen; pragmatics; speech act; strategy

\title{
PENDAHULUAN
}

Manusia yang merupakan makhluk sosial pasti membutuhkan orang lain dalam menjalani kehidupan sehari-hari. Dalam menjalani kehidupan sehari-hari tersebut manusia berkomunikasi dan berinteraksi satu sama 
lainnya. Ketika orang lain sedang dalam keadaan yang tidak diinginkannya atau berada dalam masalah, manusia yang hakikatnya sebagai makhluk sosial yang hidup berdampingan satu sama lain pasti ingin membantu orang tersebut agar bisa keluar dari keadaan yang tidak diinginkan tersebut. Bantuan tersebut bisa berupa material maupun non material. Bantuan non material tersebut dapat dilakukan dengan mengujarkan sesuatu tentang apa yang sebaiknya bisa dilakukan oleh orang lain agar orang yang bersangkutan keluar dari masalahnya atau situasi yang tidak diinginkannya. Bantuan berupa ujaran tersebut merupakan sebuah nasihat. Dalam kamus besar bahasa Indonesia edisi baru (Team Pustaka Phoenix 2007: 579) nasihat merupakan ajaran atau pelajaran baik, anjuran, petunjuk, peringatan, teguran yang baik; ibarat yang terkandung dalan sesuatu cerita dan sebagainya. Dalam bahasa Jepang sendiri nasihat disebut sebagai jogen (助言). Menurut Kumatoridani dan Murakami (dalam Takahashi 2017:14) nasihat (jogen) merupakan suatu usaha penutur untuk mengubah keadaan lawan tutur agar menjadi lebih baik melalui pendapat yang diujarkannya. Pendapat tersebut berdasarkan penilaian penutur terhadap situasi yang dialami oleh lawan tutur. Jadi dapat dikatakan bahwa ketika seseorang memberikan nasihatnya (jogen) kepada orang lain yang sedang berada dalam keadaan yang tidak diinginkannya maka orang tersebut mengemukakan sesuatu agar orang lain tersebut dapat menyelesaikan masalah.

Meskipun nasihat diujarkan untuk kebaikan orang lain tetapi bila orang lain tersebut tidak sedang meminta bantuan kepada kita mungkin saja kita dapat menyinggung orang lain tersebut. Seperti yang dinyatakan oleh DeCapuan dan Huber (dalam Bayraktaroglu dan Sifianou, 2001: 180) bahwa dalam situasi informal:

“ Memberikan nasihat berarti menyatakan beberapa kemampuan yang tidak ditanyakan atau diinginkan oleh penerima, serta memperkirakan hal yang benar pada situasi tersebut, membuat penilaian, dan memberikan arahan. Penerima bisa menafsirkan nasihat yang 
diberikan sebagai kritik negatif dan penghinaan terhadap kemampuan sosial penerima"

Sehingga dapat disimpulkan bahwa saat mengutarakan nasihat diperlukannya untuk melihat situasi apakah orang yang bersangkutan memang memintanya atau tidak dan bentuk tuturan yang diujarkan oleh penutur. Karena setiap orang mempunyai kebebasan untuk melakukan hal yang diinginkan tanpa dibatasi oleh apapun. Seperti yang dijelaskan oleh Brown dan Levinson (1987:61) “Face atau Wajah" merupakan citra diri yang setiap orang ingin miliki untuk dirinya, terdiri dari dua aspek : (a) wajah negatif : hal dasar untuk memiliki teritori, mempertahankan kepentingan pribadi, keinginan untuk tidak diganggu - dengan kata lain kebebasan untuk bertindak dan kebebasan dari gangguan (b) wajah positif : keinginan agar citra diri sendiri atau kepribadiannya dihargai dan disetujui oleh orang lain.

Dengan konsep wajah tersebut terlihat bahwa setiap orang merasa ingin dihargai dan merasa ingin kebebasannya dalam bertindak tidak diganggu oleh orang lain. Dengan mengutarakan nasihat maka kita membatasi orang lain melakukan sesuatu meskipun tuturan yang kita ujarkan demi kebaikan lawan bicara. Hal ini bisa disebut sebagai mengancam wajah negatif lawan tutur. Dengan begitu pemilihan bentuk tuturan dalam penyampaian nasihat dan strategi dalam penyampaian nasihat juga diperlukan. Hal ini karena pemilihan strategi dalam menyampaikan nasihat mungkin akan berbeda setiap orangnya, penyampaian nasihat dari teman yang akrab dengan dari penutur yang lebih tua mungkin akan berbeda. Maka dari itu tuturan nasihat bisa diucapkan dengan berbagai bentuk. Untuk tuturan nasihat (jogen) sendiri Kumatoridani dan Murakami (dalam Takahashi 2017 : 14) membagi strategi dalam menyampaikan nasihat menjadi : (a) X の提示 yaitu penutur mengujarkan tindakan yang sebaiknya dilakukan oleh lawan tutur, (b) S1 の 提示 yaitu mengujarkan situasi sekarang atau di masa depan yang tidak diinginkan oleh lawan tutur, (c) S2 の提示 yaitu penutur mengujarkan situasi yang lebih diinginkan oleh lawan tutur, serta (d) X+S1 の提示, (e) $X+S 2$ の提 
示, (f) $\mathrm{S} 1+\mathrm{S} 2$ の提示, dan (g) $\mathrm{X}+\mathrm{S} 1+\mathrm{S} 2$ の提示 yang merupakan kombinasi dari strategi (a) sampai (c).

Pada penelitian kali ini peneliti tertarik untuk mengambil data tindak tutur nasihat (jogen) dalam film pada jenis live action. Film yang diambil adalah yang berlatar kehidupan sehari-hari anak SMA, hal ini dikarenakan kehidupan SMA yang merupakan masa remaja yang dimana masa pencarian identitas dan terdapat berbagai konflik seperti antar teman sebaya maupun orang dengan yang lebih tua. Dengan kepribadian karakter dan masalah yang dimiliki oleh masing-masing karakter pada film, untuk menyelesaikan masalah tersebut diperlukan nasihat dari orang lain. Sehingga banyak memuat tuturan yang diperlukan sebagai sumber data dalam penelitian ini. Maka pada penelitian kali ini peneliti akan membahas tentang bentuk tuturan nasihat (jogen) dan strategi tindak tutur nasihat (jogen) yang terdapat pada film live action

Perumusan masalah yang didapat dari latar belakang tersebut adalah bagaimanakah bentuk tuturan nasihat (jogen) dalam jenis film live action? dan bagaimanakah strategi tindak tutur nasihat (jogen) dalam jenis film live action? Berdasarkan rumusan masalah yang dikemukakan, maka tujuan pada penelitian ini adalah mengetahui bentuk tuturan nasihat (jogen) pada jenis film live action dan mengetahui strategi penyampaian nasihat (jogen) pada jenis film live action.

Hasil penelitian ini dapat digunakan untuk menjadi referensi bagi pembelajar bahasa Jepang mengenai materi jogen.Selain itu hasil penelitian ini diharapkan dapat sebagai pertimbangan bahwa realisasi tindak tutur nasihat (jogen) harus memperhatikan hubungan antar partisipan dan bobot masalah yang dihadapi oleh lawan tutur. Serta dapat dijadikan tolak ukur pembelajar bahasa Jepang pada saat berkomunikasi dengan bahasa Jepang, khususnya dengan orang Jepang. 


\section{TINJAUAN PUSTAKA}

\section{Tindak Tutur}

Kajian tindak tutur pertama kali dikemukakan oleh John L. Austin. Pada ceramahnya yang disampaikan oleh filsuf berkebangsaan Inggris ini pada tahun 1955 di Universitas Harvard, Austin mengatakan bahwa pada dasarnya saat seseorang mengatakan sesuatu, dia juga melakukan sesuatu (dalam Nadar 2009: 11). Misalnya ketika seseorang mengatakan "I promise I will come on time"maka orang yang bersangkutan tidak hanya mengucapkan tetapi juga melakukan tindakan berjanji. Yule (2014: 82) pun berpendapat bahwa tindakan - tindakan yang ditampilkan lewat tuturan disebut tindak tutur.

Lalu menurut Aslinda dan Syafyahya (2014:34) wujud tindak tutur yang akan digunakan seseorang bergantung pada beberapa faktor, yaitu: (1) bahasa apa yang harus digunakan saat ia bertutur, (2) siapa lawan tuturnya, (3) dalam situasi bagaimana tuturan itu disampaikan, dan (4) kemungkinankemungkinan struktur manakah yang ada dalam bahasa yang digunakan. Faktor-faktor yang mempengaruhi wujud tindak tutur itu dapat diketahui dengan melihat peristiwa tutur yang terjadi saat tuturan tersebut berlangsung. Menurut Yule (2014: 82) yang dimaksud dengan peristiwa tutur merupakan keadaan disekitar lingkungan tuturan tersebut, yang membantu penutur dan pendengar. Peristiwa tutur itulah yang menentukan penafsiaran terhadap suatu tuturan ketika menentukan suatu tindak tutur. Hymes menjelaskan bahwa peristiwa tutur meliputi delapan komponen. Kedelapan komponen tersebut bila diakronimkan menjadi SPEAKING. Berikut penjelasan dari masing-masing komponen (dalam Wadghaugh yang juga dikutip dalam Chaer dan Agustina 2004:48-49):

1. S yang merupakan Setting and Scene. Setting merupakan waktu dan tempat tuturan berlangsung, misalnya di kantin, di ruang tamu, dan lain sebagainya. Lalu Scene merupakan situasi tempat dan waktu tuturan terjadi atau bisa juga mengacu pada psikologis pembicara, seperti akrab, menegangkan dan lain sebagainya. 
2. $\mathbf{P}$ yang merupakan Participant, yaitu pihak yang terlibat dalam pertuturan, seperti penutur dan petutur, penulis dan pembaca, dan lain sebagainya.

3. E yang merupakan Ends, yaitu maksud dan tujuan pertuturan, misalnya peristiwa tutur yang terjadi di dalam kelas saat kegiatan belajar mengajar berlangsung memiliki tujuan agar murid-murid tersebut paham dengan materi yang disampaikan oleh guru mendapatkan pengetahuan baru.

4. A yang merupakan Acts sequence, yaitu bentuk ujaran dan isi ujaran dalam suatu pertuturan. Bentuk ujaran mengacu pada katakata yang digunakan, bagaimana pernggunaanya dan hubungan antara apa yang dikatakan dengan topik pembicaraan.

5. K yang merupakan Key, yaitu nada, cara yang digunakan oleh penutur dalam menyampaikan tuturannya, misalnya dengan gembira, marah, tegas dan sebagainya.

6. I yang merupakan Instrumentalities, yaitu jalur bahasa yang digunakan saat menyampaikan pesan, misalnya lisan, tertulis, melalui telepon.

7. $\mathbf{N}$ yang merupakan Norms of interaction and interpretation, yaitu norma atau aturan interaksi yang berlaku dalam pertuturan, misalnya cara memohon, cara menginterupsi dan sebagainya. Komponen ini juga mengacu pada norma penafsiran terhadap ujaran dari lawan tutur.

8. G yang merupakan Genre, yaitu jenis bentuk penyampaian tuturan, seperti dialog, monolog, naskah, puisi dan sebagainya.

\section{Nasihat (Jogen)}

Nasihat termasuk kedalam tindak tutur direktif. Dalam kamus besar bahasa Indonesia (Team Pustaka Phoenix 2007 : 597) nasihat merupakan ajaran atau pelajaran baik, anjuran, petunjuk, peringatan, teguran yang baik, ibarat yang terkandung dalam suatu cerita dan sebagainya. Pengertian dalam 
kamus Oxford (Oxford University Press, 2011: 7) advice is opinion given to somebody about what they should do.

Nasihat tersebut dalam bahasa jepang merupakan jogen (助言). Seperti yang dijelaskan dalam Kotobank 助言は助けになるような意見や言葉を、そ ばから言ってやること。Uogen adalah mengucapkan pikiran atau kata-kata yang dapat membantu). Searle pun mengatakan (dalam Limberg dan Locher 2012: 3) speech act advice "telling you what is best for you". Menurut Kumatoridani dan Murakami (dalam Takahashi 2017: 14) menjelaskan bahwa:

助言は「話し手の現状認識・評価に基づき聞き手の現在もしく は将来おかれる状況を聞き手の行為によってより望ましい状況 に変えさせようとする意図のもとに遂行される発話行為」。助 言意図を表現する形式のプロトタイプとして、'Do X for S2 because S1 (is not desirable)'

Yang bisa dimaknai sebagai berikut:

Pengertian jogen (nasihat) adalah berusaha merubah keadaan lawan bicara yang sekarang sedang terjadi atau di masa yang akan datang, menjadi keadaan yang diinginkan oleh lawan bicara dengan perbuatan yang dilakukan lawan bicara berdasarkan pengakuan dan penilaian dari pembicara. Berdasarkan gambaran dari Jogen tersebut maka 'Do X for S2 because S1 (is not desirable)'

Berdasarkan pengertian yang dikemukakan oleh para ahli di atas dapat dikatakan bahwa nasihat (jogen) merupakan opini atau pendapat yang diujarkan oleh penutur untuk membantu lawan tutur mengubah keadaan agar menjadi lebih baik. Untuk mencapai suatu tujuan dari tindak tutur Searle berpendapat harus ada kondisi dan kriteria yang harus dipenuhi. Situasi dan kriteria tersebut adalah felicity condition. Felicity condition dari nasihat menurut Searle (1969:87) adalah sebagai berikut:

1. Propotional Content Condition: Tindakan pendengar di masa depan

2. The Prepotary Condition: (a) Pembicara memiliki alasan untuk percaya bahwa tindakan tersebut menguntungkan pendengar (b) 
tidak diketahui oleh pembicara atau pendengar kalau pendengar akan melakukan tindakan itu dalam kondisi normal

3. Sincerity Condition: Pembicara percaya bahwa tindakan tersebut menguntungkan pendengar

4. Essential Condition: Hasil dari tindakan itu adalah keuntungan terbaik pendengar

Dapat dikatakan secara singkat bahwa tindak tutur nasihat itu bila penutur mengucapkan sesuatu yang penurtur percaya akan menguntungkan lawan tutur dimasa depan. Berdasarkan teori tindak tutur dalam bahasa Jepang, Kumadoritani dan Murakami (dalam Takahashi 2017: 13) menjelaskan bahwa secara pragmatik yang dimaksud dengan tindak tutur nasihat (jogen) adalah sebagai berikut:

1. Berusaha mengubah situasi yang sedang dialami atau yang akan dialami oleh lawan bicara (S1) menjadi situasi yang berbeda (S2)

2. Berdasarkan pengakuan dan penilaian dari pembicara Jogen direalisasikan sebagai berikut :

a. S1 adalah situasi yang dialami sekarang oleh lawan bicara, atau yang menurut pembicara merupakan situasi yang tidak diinginkan oleh lawan bicara.

b. S2 adalah situasi yang lebih diinginkan oleh lawan bicara.

c. Untuk mewujudkan S2 diperlukannya pergerakan X lawan bicara.

3. Pembicara percaya bahwa kalau tidak melakukan tindak tutur nasihat (jogen), maka lawan bicara tidak akan bertindak untuk menghasilkan S2.

4. Tindakan yang dianggap tepat agar target dapat mencapai tujuan tertentu

5. Berlaku untuk diterima atau ditolak 
Secara singkat dapat disimpulkan bahwa ketika lawan tutur mengalami situasi yang tidak diinginkan maka penutur percaya bahwa ia harus mengatakan tindak tutur nasihat (jogen) tersebut agar lawan tutur melakukan tindakan yang dapat mengubah situasi yang sedang lawan tutur alami menjadi situasi yang lebih baik atau lebih diinginkan. Prototipe dari nasihat (jogen) adalah sebagai berikut :

“Do X for S2 because S1 (is not disireable)"

Yang bisa dimaknai dengan:

Lakukan X untuk mewujudkan S2 karena S1 (tidak diinginkan)

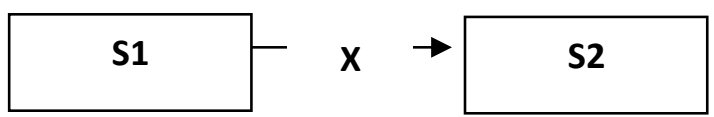

Yang dimana menurut penilaian penutur:

- S1 (Situation 1) merupakan keadaan atau situasi yang sedang dialami atau yang akan dialami oleh lawan tutur

- X (Tindakan) merupakan tuturan yang mengandung maksud tindakan apa yang sebaiknya dilakukan oleh lawan tutur untuk merubah situasi

- S2 (Situation 2) merupakan keadaan yang lebih baik atau yang lebih diinginkan oleh lawan tutur

\section{Strategi Penyampaian Nasihat (Jogen)}

Kumatoridani dan Murakami (dalam Takahashi 2017 :14) mengatakan bahwa dalam menyampaikan nasihat didasarkan pada penilain penutur terhadap situasi yang sedang dialami lawan tutur dan bagaimana tindakan yang harus diambil berdasarkan situasi tersebut agar menjadi situasi yang diinginkan oleh lawan tutur, maka berdasarkan pendapat tersebut dalam menyampaikan nasihat terdapat beberapa strategi yaitu, sebagai berikut: 
1. Menunjukkan X (X の提示): penutur mengutarakan secara jelas dalam tuturan yang diujarkan oleh penutur tentang apa yang sebaiknya dilakukan oleh lawan tutur, seperti「新しいのに入れ替 えればいいじゃん」(ganti saja dengan yang baru)

2. Menunjukan S1 (S1 の提示): penutur mengutarakan apa yang lawan tutur lakukan sekarang akan berdampak kepada situasi yang tidak diinginkan di masa yang akan datang atau penutur mengutarakan situasi saat ini yang tidak diinginkan oleh lawan tutur menurut penilaiannya, seperti (i) ハンカチ落とされましたよ (ii)「それ食べるとご飯食べれなくなるよ」 (i. selampemu terjatuh, ii. Kalau makan itu nanti tidak bisa makan nasi loh)

3. Menunjukan S2 (S2 の提示): penutur mengutarakan situasi yang menurut penilaian penutur merupakan situasi yang lebih diiinginkan oleh lawan tutur, seperti「座敷が温かいけえ(ruang tataminya hangat). Sering kali mengambil bentuk " 22 is better"

4. Menunjukan $\mathrm{X}+\mathrm{S} 1(\mathrm{X}+\mathrm{S} 1$ の提示): penutur mengutarakan situasi sekarang yang menurut penutur merupakan situasi yang tidak diinginkan oleh lawan tutur (S1) sebagai alasan agar lawan tutur melakukan tindakan yang sebaiknya dilakukan sesuai dengan yang penutur ujarkan (X), seperti「B ちゃん、風邪ひいとるんじゃけえ、 長袖来た方がいいよ」(B, masuk angin ya, lebih baik kau datang dengan lengan panjang)

5. Menunjukan $\mathrm{X}+\mathrm{S} 2(\mathrm{X}+\mathrm{S} 2$ の提示): penutur mengutarakan apa yang sebaiknya dilakukan lawan (X) tutur kemudian mengutarakan hal yang akan berubah (S2) kalau lawan tutur melakukan hal tersebut, seperti「目薬入れたら?ちょっとは違うよ」( Bagaimana kalau pakai obat mata? Nanti lebih enakan loh). Bentuknya adalah 'if you do $X$, then $S 2$ will result.' 
6. Menunjukan $\mathrm{S} 1+\mathrm{S} 2(\mathrm{~S} 1+\mathrm{S} 2$ の提示): penutur mengutarakan hal yang nanti nantinya tidak diinginkan oleh lawan tutur atau mengutarakan apa yang sekarang dilakukan oleh lawan tutur (S1) kemudian mengutarakan keadaan yang menurut penutur merupakan keadaan yang lebih baik atau lebih diinginkan oleh lawan tutur (S2) sebagai pertimbangan agar lawan tutur melakukan sesuatu, seperti「H 大学に進んでも君のやりたい勉強はできない よ。でも、T大学ならそれが可能だよ」( Kalau ingin melanjutkan belajar seperti yang kau mau ke universitas $\mathrm{H}$ tidak akan bisa loh. Tapi kalau ke universitas $\mathrm{T}$ ada kemungkinan bisa)

7. Menunjukan $\mathrm{X}+\mathrm{S} 1+\mathrm{S} 2(\mathrm{~S} 1+\mathrm{S} 2$ の提示): penutur mengutarakan keadaan yang menurut penilaian penutur merupakan keadaan yang tidak diinginkan oleh lawan tutur (S1) kemudian penutur mengutarakan hal yang sebaiknya dilakukan agar kedaan tersebut berubah $(\mathrm{X})$, dan mengutarakan keadaan yang lebih baik atau lebih diinginkan oleh lawan tutur (S2), seperti「そっちに座っていると 足が痛いでしょう、こっちに座ったら?楽だよ」(Kalau duduk disitu kakimu sakit kan. Bagaimana kalau duduk disini? Lebih enak loh)

\section{METODE PENELITIAN}

\section{Lingkup Penelitian}

Ruang lingkup penelitian ini adalah linguistik karena peneliti menganalisis tindak tutur nasihat (jogen) yang termasuk kedalam pembahasan pragmatik. Tindak tutur nasihat (jogen) yang akan diteliti adalah pada bagian bentuk tuturan dan strategi penyampaian nasihat (jogen). Kemudian pemilihan strategi penyampaian nasihat (jogen) ini dapat dilihat melalui peristiwa tutur yang terjadi.Peneliti membahas tindak tutur nasihat 
(jogen) yang terdapat pada film live action. Film live action yang digunakan adalah yang membahas kehidupan anak SMA.

\section{Teknik Pengumpulan Data dan Teknik Analisis Data}

Teknik pengumpulan data yang digunakan dalam penelitian ini menggunakan metode simak dan teknik catat. Metode simak adalah peneliti melakukan penyimakan penggunaan bahasa (Mahsun 2017: 91). Peneliti menyimak percakapan maupun monolog yang dilakukan oleh tokoh yang terdapat dalam film live action. Lalu dilanjutkan dengan teknik catat yaitu peneliti mencatat beberapa bentuk yang relevan bagi penelitian dari penggunaan bahasa (Mahsun 2017: 135). Peneliti mencatat tindak tutur nasihat (jogen) yang diujarkan oleh tokoh yang terdapat dalam film live action.

Metode yang digunakan untuk analisis data pada penelitian ini adalah metode padan referensial dengan teknik dasar yaitu teknik pilah unsur penentu (PUP). Pada metode padan alat penentuanya diluar, terlepas dan tidak menjadi bagian dari bahasa (langue) yang bersangkutan (Sudaryanto 1993: 13). Dengan metode padan referensial ini objek yang akan diteliti dipadankan dengan referen penentunya (Muhammad 2011: 234). Referen pada penelitian kali ini adalah konsep nasihat (jogen) dan konteks tuturan berdasarkan teori SPEAKIG. Alat teknik pilah unsur penentu (PUP) ini adalah kemampuan peneliti dalam memilah data tersebut. Kemampuan memilah ini bersifat mental, mengandalkan intuisi dan menggunakan pengetahuan teoritis (Muhammad, 2011: 239).

\section{HASIL DAN PEMBAHASAN}

Berikut merupakan jawaban dari permasalahan penelitian ini:

Bentuk tuturan dan strategi penyampaian nasihat di atas dapat dipahami bahwa pemilihan bentuk tuturan dan strategi penyampaian nasihat 
(jogen) tergantung dari hubungan antar partisipan dan masalah yang dialami oleh lawan tutur, sebagai berikut:

1. Pada jenis hubungan akrab antar teman sebaya sebagian besar pemberian nasihat (jogen) dilakukan saat masalah yang dialami oleh lawan tutur adalah kalau lawan tutur saat itu sedang berada dalam situasi yang tidak diinginkannya. Nasihat (jogen) yang diberikan pun berupa saran tentang apa yang sebaiknya dilakukan oleh lawan tutur atau bisa disebut dengan strategi X の提示 seperti お母さんがどこかで見てるならさ、笑ってたほうがいいんじゃ ん. Hal ini sesuai dengan teori yang dikemukakan oleh Brown dan Levinson yang menyebutkan bahwa penutur lebih mudah memberikan saran kepada orang yang dianggapnya dekat, sehingga jogen yang diberikan pun menggunakan tuturan saran. Tetapi bila masalah yang dialami oleh lawan tutur adalah ketika ia melakukan suatu tindakan yang akan merugikan diri sendiri maka strategi yang digunakan pun tidak hanya $\mathrm{X}$ の提示, tetapi bisa dikombinasikan dengan strategi lain menjadi $\mathrm{X}+\mathrm{S} 1$ の提示 maupun $\mathrm{X}+\mathrm{S} 1+\mathrm{S} 2$ の提 示 dan bentuk tuturan nasihat yang digunakan pun tidak hanya berupa saran tetapi dalam bentuk opini, dugaan, maupun pengandaian.

2. Pada jenis hubungan sebaya tetapi tidak akrab sebagian besar pemberian nasihat (jogen) dilakukan saat masalah yang dialami oleh lawan tutur adalah ketika lawan tutur melakukan suatu tindakan yang akan merugikan dirinya sendiri dimasa yang akan datang. Nasihat (jogen) yang diberikan berupa gambaran tentang akibat dari perbuatannya tersebut, bisa berupa situasi yang tidak diinginkan oleh lawan tutur (S1) maupun memberitahukan situasi yang lebih baik atau situasi yang lebih diinginkan oleh lawan tutur (S2). Strategi yang digunakan untuk menyampaikan nasihat (jogen) 
tersebut adalah S1 の提示 seperti 我慢ばっかしてたら。。。自分 が損する maupun S2 の提示 seperti そういう風にちゃんと言葉 にすれば伝わせるし、拒否る奴いねーと思うよ. Tetapi tidak memungkinkan juga untuk nasihat (jogen) tersebut disampaikan dalam bentuk saran dengan strategi $\mathrm{X}+\mathrm{S} 1+\mathrm{S} 2$ の提示 yaitu penutur memberikan saran (X) agar lawan tutur mencapai situasi yang lebih diinginkannya (S2) karena menurut situasi sekarang tidak diinginkan oleh lawan tutur (S1). Atau dengan strategi X の提示 saja. Hal ini sesuai dengan yang dikemukakan oleh Brown dan Levinson bahwa faktor mendesak dan pentingnya saran mempengaruhi pembentukan saran, sehingga pada saat lawan tutur melakukan sesuatu yang dapat merugikannya maka penutur menuturkan nasihat tanpa memperhatikan jarak sosial. Meskipun menggunakan strategi $\mathrm{X}$ の提示 tetapi pada bentuk tuturan yang digunakan menggunakan penyampaian yang sudah diperhalus seperti 〜んじゃないの・と思う・か.

3. Pada jenis hubungan penutur yang memiliki usia lebih tua maka pemberian nasihat (jogen) dilakukan ketika lawan tutur sedang berada dalam situasi yang tidak diinginkannya maupun bila lawan tutur melakukan tindakan yang akan merugikan dirinya sendiri dimasa yang akan datang. Strategi yang digunakan pun diucapkan dalam bentuk perintah atau larangan disertai dengan akibat dari perbuatan lawan tutur dimasa yang akan datang sebagai peringatan yaitu dengan strategi X+S1 の提示 seperti なんか。。。わけわか んないけどよ、人のせいにすんな $(\mathrm{X})$ 。人のせいにしてもな、何 も解決しねんだ(S1)。世の中だってよ理不尽なことばっかりだ けど、結局自分で何とかしかねんだよ(X). Selain strategi tersebut strategi X の提示 pun digunakan. Jika melihat dari teori 
yang dikemukakan oleh Brown dan Levinson maka faktor yang mempengaruhi saat memberikan nasihat (jogen) tersebut adalah faktor penting dan mendesaknya serta jarak sosial dan power. Hal ini mengisyaratkan bahwa bila seseorang yang lebih tua memiliki pengalaman yang lebih. Sehingga dapat secara langsung memberikan peringatan bila lawan tutur melakukan sesuatu yang akan merugikan dirinya sendiri.

\section{KESIMPULAN DAN SARAN}

Berdasarkan hasil penelitian dapat disimpulkan bahwa pemilihan bentuk tuturan dan strategi penyampaian nasihat (jogen) tergantung dari hubungan antar partisipan dan masalah yang dialami oleh lawan tutur. Kemudian terdapat beberapa saran yaitu, baiknya untuk penelitian selanjutnya bisa menggunakan sumber data jitsurei seperti pada reality show, talk show atau program TV lain. Kemudian karena pada penelitian kali ini tidak membahas tentang pelanggaran maksim dalam menyampaikan nasihat (jogen) maka pada penelitian selanjutnya bisa menganalisis tentang pelanggaran maksim tersebut, serta bisa mengkombinasikan antara maksim dan strategi penyampaian nasihat. Selain itu juga bisa meneliti tentangbagaimana penyampaian strategi nasihat (jogen) yang dipengaruhi oleh jenis kelamin.

\section{REFERENSI}

Aslinda, A., \& Syafyahya, L. (2014). Pengantar sosiolinguistik. PT Refika Aditama.

Bayraktaroglu, A., \& Sifianou, M. (ed). (2001). Linguistic politeness across boundaries: The case of Greek and Turkish, 177-208. Diakses pada Desember, 2, 2019, dari https://books.google.co.id/books?id=U7pv079csCEC\&printsec=frontcov 
er\&dq=linguistic + politeness+across+boundaries\&hl=id\&sa=X\&ved=0ah UKEwidvurKi5znAhXJYisKHezjDG8Q6AEIJzAA\#v=onepage\&q=linguistic \%20politeness $\% 20$ across $\% 20$ boundaries\&f=false

Brown, P., \& Levinson, S. (1987). Politeness some universals in language usage. Cambrige Press University.

Chaer, A., \& Agustina, L. (2004). Sosiolinguistik perkenalan awal. PT Rineka Cipta.

Kotobank. (n.d.). Jogen. Dalam Kotobank.jp dictionary. Diakses pada Desember 2, 2019, dari https://kotobank.jp/word/\%E5\%8A\%A9\%E8\%A8\%80-80315

Limberg, H., \& Locher, M. A. (2012). Advice in discourse. John Benjamins Publishing.

Mahsun, M. (2017). Metode penelitian bahasa: Tahapan, strategi, metode dan tekniknya-Edisi 3-Cetakan 9. Rajawali Pers.

Muhammad, M. (2011). Metode penelitian bahasa. Ar Ruzz Media.

Nadar, F. X. (2009). Pragmatik dan penelitian pragmatik. Graha Ilmu.

Oxford Learner's Pocket Dictionary Fourth Edition. (2011). Oxford University Press. 2011.

Searle, J. R. (1969). Speech acts: An essay in the philosophy of language. Cambrige Univesity Press.

Sudaryanto, S. (1993). Metode dan aneka teknik analisis bahasa: Pengantar penelitian wahana kebudayaan secara linguistik. Duta Wacana University Press.

Takahashi, C. (2017). Hatsuwa koui toshite no jogen ni tsuite no takakuteki kenkyuu - hatsuwa koui riron ni yoru tokuchou no kijutsu to kaiwa bunseki ni yoru nihongo no jogen sougo koui no kijutsu-. Disertasi. Kyouto Daigaku. Kufs.repo.nii.ac.jp

Team Pustaka Phoenix. (2007). Kamus besar bahasa Indonesia edisi baru. Pustaka Phoenix.

Yule, G. (2014). Pragmatik. Pustaka Pelajar. 